\title{
The Key Steps in Robotic Radical Prostatectomy
}

\author{
(1) Bora Özveren, (1) Levent Türkeri \\ Acıbadem Mehmet Ali Aydınlar University Faculty of Medicine, Department of Urology, Istanbul, Turkey
}

Robot-assisted laparoscopic radical prostatectomy (RARP) has become the standard of care in the surgical management of clinically localized prostate cancer. Technical refinements with robotic technology such as bladder neck preservation and vesicourethral reconstruction offer improved functional recovery, especially in the urinary domain and increased oncological efficiency by decreasing rates of positive surgical margins. Since the initial description in 2001, several novel approaches in operative techniques were proposed in order to improve oncological and functional outcomes. This video presents the surgical key-steps of two different techniques of RARP.

\section{RARP-Posterior Approach}

The onset of the posterior approach consisted of the release and vascular control of vasa deferentia (VDs) and seminal vesicles (SVs) along with the dissection of the prostate away from the rectum at the plane of Denonvillier's fascia. After dropping of the urinary bladder, the space of Retzius was accessed and the endopelvic fascia was incised. The lateral prostatic fascia was released from the levator ani muscle fibers and the prostate was mobilized on both sides. The dorsal vascular complex (DVC) was then ligated using a CT- 1 needle and 0 polyglactin suture with a slip-knot, without a periurethral suspension-stitch. Once the bladder neck was identified and transected, the retrotrigonal fibromuscular layer was sectioned to gain access to the VDs and SVs. After Hem-o-Lok ${ }^{\mathrm{TM}}$ clipping of the lateral pedicle vessels, a high anterior release of lateral pelvic fascia was performed anteromedially on each side, allowing the layer of tissue containing the neurovascular structures to be dissected free. A posterior reconstruction of the musculofascial layer was utilized by a Monocryl Rocco-stitch. Finally, the urethrovesical anastomosis was performed according to Van Velthoven's method using two sets of 3-0 V-LOC ${ }^{\mathrm{TM}}$, beginning at $6 \mathrm{o}^{\prime} \mathrm{clock}$ with one clockwise and another counterclockwise continuous suture until 12 o'clock.

\section{RARP-Retzius-Sparing Approach}

Following a $5-\mathrm{cm}$ horizontal incision of the peritoneum overlying the pouch of Douglas the VDs were identified and transected. The anterior and posterior surfaces of the SVs were progressively dissected and the tips of the SVs were released while avoiding extensive dissection into the posterolateral neurovascular structures. The avascular plane of Denonvilliers'fascia that separates the prostate from the anterior rectal wall was cut to enter the interfascial plane of dissection. The planes between the prostatic and DV fasciae in the posterior and the posterolateral aspect of the prostate gland were developed to maximize nerve preservation, through both intra- and inter-fascial dissection. After a triangular space has been developed at the base of the prostate gland, arteries that coursed from the NVB toward the gland were dissected, clipped, and divided. The subsequent inter- and intra-fascial release of the NVB away from the prostate was guided by the whitish surface of the prostatic capsule along the curve of the lateral surface of the midprostate toward the apex. With retraction of the peritoneum covering the bladder upward, the trigone of the bladder was progressively detached from the base of the prostate gland. Consequently, the bladder neck was transected at the posterior aspect. The subsequent dissection of the ventral prostatic surface completely spared the pubovesical complex comprising the detrusor apron with the associated pubovesical ligaments and the DVC. The urethra was then circumferentially dissected and sharply transected. A running urethrovesical anastomosis was finally performed

Cite this article as: Özveren B, Türkeri L. The Key Steps in Robotic Radical Prostatectomy. Bull Urooncol 2020;19(1):47-48

Address for Correspondence: Bora Özveren, Acıbadem Mehmet Ali Aydınlar University Faculty of Medicine, Department of Urology, İstanbul, Turkey

E-mail: bora.ozveren@acibadem.edu.tr ORCID-ID: orcid.org/0000-0001-8902-7530 Received: 16.02.2020 Accepted: 03.03.2020

(c) Copyright 2020 by Urooncology Association Bulletin of Urooncology / Published by Galenos Yayınevi 
with two sets of 3-0 V-lock ${ }^{\text {TM }}$ running sutures, beginning at 12 o'clock, with one clockwise and another counterclockwise until 6 o'clock.

\section{Acknowledgements}

Publication: The results of the study were not published in full or in part in form of abstracts. References to illustrations reproduced with permission.

Contribution: Prof Dr Li-Ming Su granted permission to use diagrams of the steps of robotic radical prostatectomy. All copyright belongs to Li-Ming Su, MD, University of Florida Health.

Conflict of Interest: No conflict of interest was declared by the authors.

Financial Disclosure: The authors declared that this study received no financial support.

\section{Ethics}

Informed Consent: Patient approval was obtained.

Peer-review: Externally and internally peer-reviewed.

\section{Authorship Contributions}

Surgical and Medical Practices: L.T., B.Ö., Concept: L.T., Design: L.T., B.Ö., Data Collection or Processing: B.Ö., Analysis or Interpretation: L.T., B.Ö., Literature Search: B.Ö., Writing: B.Ö., L.T.

\section{References}

1. Turpen R., Atalah H., Su LM. (2011) Transperitoneal Robot-Assisted Laparoscopic Radical Prostatectomy: Posterior Approach. In: Su LM. (eds) Atlas of Robotic Urologic Surgery. Current Clinical Urology. Humana Press

2. Asimakopoulos, A.D., Miano, R., Galfano, A., Bocciardi, A.M., Vespasiani, G., Spera, E. and Gaston, R. (2015), Retzius-sparing robot-assisted laparoscopic radical prostatectomy: Critical appraisal of the anatomic landmarks for a complete intrafascial approach. Clin. Anat., 28: 896-902. doi:10.1002/ca.22576

3. Walz J, Burnett AL, Costello AJ, et al. A critical analysis of the current knowledge of surgical anatomy related to optimization of cancer control and preservation of continence and erection in candidates for radical prostatectomy. Eur Urol 2010; 57:179-192 